\title{
Ligand design for site-selective installation of Pd and Pt centers to generate homo- and heteropolymetallic motifs $\dagger$
}

\author{
Daniel L. M. Suess and Jonas C. Peters* \\ Received 15th February 2010, Accepted 18th June 2010 \\ DOI: $10.1039 / \mathbf{c 0 0 3 1 6 3 a}$
}

The modular synthesis of a series of nitrogen-rich polydentate ligands that feature a common pincer-type framework is reported. These ligands allow for site-selective installation of palladium and platinum to give rise to bi- and trimetallic complexes that have $d^{8}-d^{8}$ interactions.

Natural and synthetic polymetallic reaction sites mediate a wide range of small molecule transformations that have not been realized in monometallic analogs. ${ }^{1}$ For example, synthetic bimetallic complexes that contain $\mathrm{d}^{8}-\mathrm{d}^{8}$ interactions display unusual photochemical reactivity ${ }^{2}$ and have interesting electronic structures ${ }^{3}$ owing to the metal-metal orbital interaction. Studies of these systems - and of polymetallic complexes more generally - are enhanced by the synthetic ability to rationally generate specific homo- and heteropolymetallics of interest. ${ }^{4}$ We are beginning to explore the synthesis and siteselective metallation of polynucleating ligands in order to generate such complexes. Reported herein are initial efforts toward the preparation of nitrogen-rich ligands that feature a common pincer-type framework. We establish the utility of this family of ligands for the site-selective installation of $\mathrm{Pd}$ and $\mathrm{Pt}$ centers which can result in bi- and trimetallic systems featuring $d^{8}-d^{8}$ interactions in the solid-state and in solution.

The four ligands described in this communication feature two or three tridentate binding sites. Common to each ligand is a monoanionic, bis(quinolinyl)amide (BQA) pincer-type binding site. Decoration of the pincer scaffold with one or two neutral binding sites affords access to the polymetallic complexes of interest herein. We have chosen in this initial investigation to target $\mathrm{Pd}$ and $\mathrm{Pt}$ species due to our prior experience with the chemistry of group 10 BQA complexes, ${ }^{5}$ and due to their low lability by comparison to first row late metals.

The ligand synthesis of the dinucleating $\mathrm{Ll}^{\mathrm{R}} \mathrm{H}$ series (Scheme 1) is accomplished in three steps from 8-bromo-2methylquinoline (1). Oxidation of 1 with $\mathrm{SeO}_{2}$ provides access to aldehyde 2 . Reductive amination of 2 with $\mathrm{NaHB}(\mathrm{OAc})_{3}$ and the appropriate secondary amine installs the neutral tridentate binding sites in amine intermediates 3, 4, and 5. The BQA binding pocket is generated by $\mathrm{Pd}$-mediated $\mathrm{C}-\mathrm{N}$ cross-coupling of 3, 4, and 5 with 8-aminoquinoline to give yellow ligands 6,7 , and $\mathbf{8},{ }^{5 a}$ respectively. The latter transformation proceeds to remarkably high conversion $(>90 \%$ ) given the potential for

Department of Chemistry, Massachusetts Institute of Technology, Cambridge, MA 02139, USA and Division of Chemistry and Chemical Engineering, California Institute of Technology, Pasadena, CA 91125, USA.E-mail: jcpeters@caltech.edu

$\dagger$ Electronic supplementary information (ESI) available: Synthetic details, crystal structure diagrams, and spectroscopic data. CCDC 766171-766176. For ESI and crystallographic data in CIF or other electronic format see DOI: $10.1039 / \mathrm{c} 003163 \mathrm{a}$

these ligands to poison the Pd cross-coupling catalyst. A nonadentate, trinucleating ligand (9) is prepared in an analogous synthesis from 5 and 8-amino-2-methylquinoline (see ESI $\dagger$ ).

The installation of $\mathrm{Pd}$ into the anionic binding site of $\mathbf{6}$ is readily achieved by reaction with $(\mathrm{COD}) \mathrm{Pd}(\mathrm{Me}) \mathrm{Cl}$ and catalytic $\mathrm{Et}_{3} \mathrm{~N}$ to form red, neutral $\mathrm{Ll}^{\mathrm{OMe}} \mathrm{PdCl} \mathbf{1 0}$ with concomitant loss of methane. Alternatively, $\mathbf{1 0}$ may be generated using (COD) $\mathrm{PdCl}_{2}$ and stoichiometric $\mathrm{Et}_{3} \mathrm{~N}$; however, the use of (COD)Pd(Me)Cl obviates the need to purify $\mathbf{1 0}$ from $\mathrm{Et}_{3} \mathrm{~N}$. $\mathrm{HCl} .{ }^{1} \mathrm{H}$ NMR spectroscopy of $\mathbf{1 0}$ shows the disappearance of the bis(quinolinyl)amine resonance. The solid-state structure ${ }^{6}$ of $\mathbf{1 0}$ (determined by X-ray crystallography, Fig. 1) confirms the installation of $\mathrm{Pd}$ into the bis(quinolinyl)amido site; the neutral bis(2-methoxyethyl)amine binding site remains open.

Reaction between 7, (COD) $\mathrm{PdCl}_{2}$, and $\mathrm{Et}_{3} \mathrm{~N}$ affords the red salt $\left[\mathrm{Ll}^{\mathrm{im}} \mathrm{Pd}\right] \mathrm{Cl} 11$, the solid-state structure ${ }^{7}$ of which demonstrates that one imidazole occupies the coordination site trans to the amide, thereby forming an eight-member ring (Fig. 1). Variable-temperature ${ }^{1} \mathrm{H}$ NMR spectroscopy reveals that the solution-state structure in $\mathrm{CDCl}_{3}$ is consistent with the solidstate structure. At low temperature $\left(\mathrm{ca} .-50{ }^{\circ} \mathrm{C}\right)$, the two imidazole rings are inequivalent and each methylene proton is coupled to its diastereotopic partner; coalescence is observed near room temperature and the averaged signals can be seen at higher temperature $\left(\mathrm{ca} .50{ }^{\circ} \mathrm{C}\right.$; see $\left.\mathrm{ESI} \dagger\right)$.

For 8 , the kinetically preferred site for metal uptake is the neutral bis((pyridin-2-yl)methyl)amine pocket; reaction of 8 with one equivalent (COD)Pd(Me)Cl and 1 equiv. $\mathrm{TlPF}_{6}$ thus provides yellow $\left[\mathrm{L1}^{\mathrm{py}}(\mathrm{H}) \mathrm{PdMe}\right]\left[\mathrm{PF}_{6}\right] \mathbf{1 2}$ with precipitation of $\mathrm{TlCl} .{ }^{1} \mathrm{H}$ NMR spectroscopy of $\mathbf{1 2}$ reveals that the bis(quinolinyl)amine $\mathrm{NH}$ proton is still present and that the methylene protons between the pyridine rings and the tertiary amine are diastereotopic. Both observations are consistent with selective metallation of the bis((pyridin-2-yl)methyl)amine binding pocket. The solid-state structure ${ }^{8}$ confirms this assignment (Fig. 1).

We were gratified to find that the BQA site of $\mathbf{1 2}$ is readily metallated with an additional equiv. of (COD) $\mathrm{Pd}(\mathrm{Me}) \mathrm{Cl}$ and catalytic $\mathrm{Et}_{3} \mathrm{~N}$ to give purple-red $\left[\mathrm{L}^{\mathrm{py}}(\mathrm{PdCl}) \mathrm{PdMe}\right]\left[\mathrm{PF}_{6}\right] 13$. The solid-state structure ${ }^{9}$ of $\mathbf{1 3}$ (Fig. 2) reveals a $\mathrm{Pd}-\mathrm{Pd} \mathrm{d}-\mathrm{d}^{8}$ interaction with an average Pd-Pd distance of 3.1909(7) A, which is less than the sum of the van der Waals radii $(3.26 \AA){ }^{10}$ This favorable zero bond order interaction has been explained by mixing of $4 \mathrm{~d}_{z^{2}}$ and $5 \mathrm{p}_{z}$ orbitals between the interacting metals. ${ }^{11}$ Among the DFT-calculated occupied orbitals are two orbitals that have $\mathrm{Pd}-\mathrm{Pd} \sigma$ and $\sigma^{*}$ character (Fig. 3). ${ }^{12}$ The ${ }^{1} \mathrm{H}$ NMR spectrum of $\mathbf{1 3}$ in $\mathrm{CDCl}_{3}$ is consistent with a $C_{\mathrm{s}}$ symmetric structure at room temperature; however, cooling the solution results in decoalescence of the signals at $c a .-40{ }^{\circ} \mathrm{C}$ and a spectrum that requires a $C_{1}$ symmetric structure at $-58{ }^{\circ} \mathrm{C}$ 


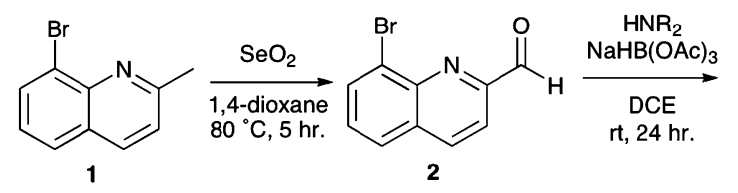<smiles>[R16]Cc1ccc2cccc(Br)c2n1</smiles>

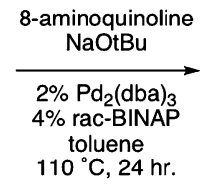
3: $R=2-$ methoxyethyl
4: $\mathrm{R}=(1-$ methylimidazole-2-yl)methyl 5: $R=($ pyridin-2-yl)methyl

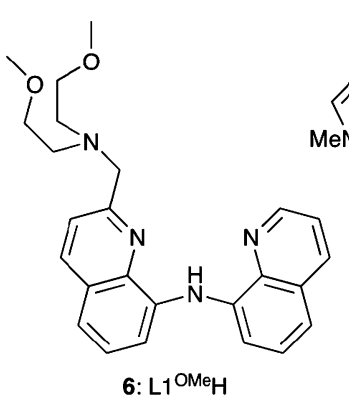

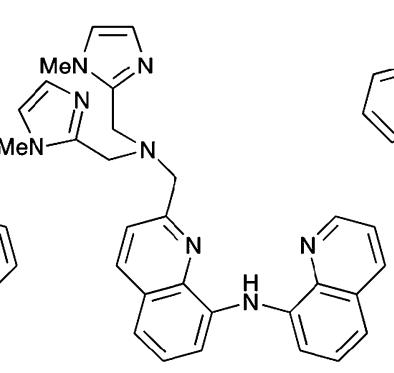

7: L1 ${ }^{\text {imH }}$

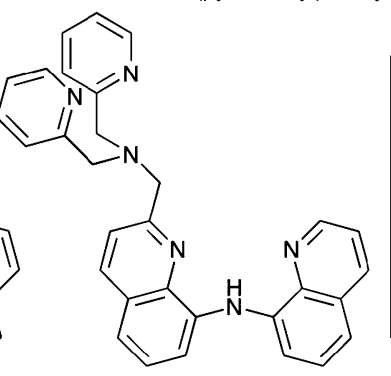

8: $L 1^{p y} H$

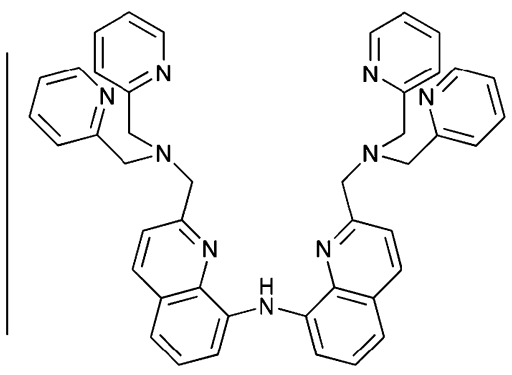

9: $\mathrm{L2}^{\mathrm{py}} \mathrm{H}$

Scheme 1 Synthesis of 6, 7, 8, and 9.

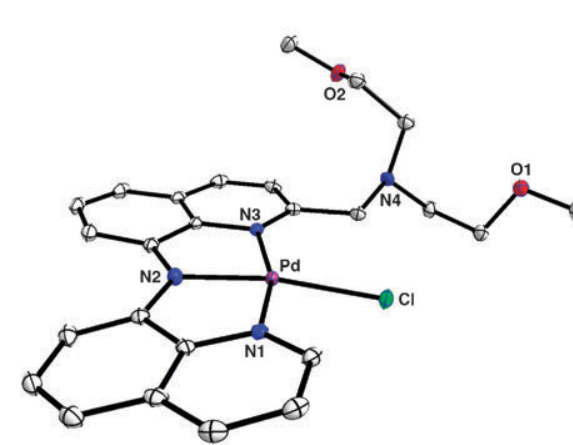

10

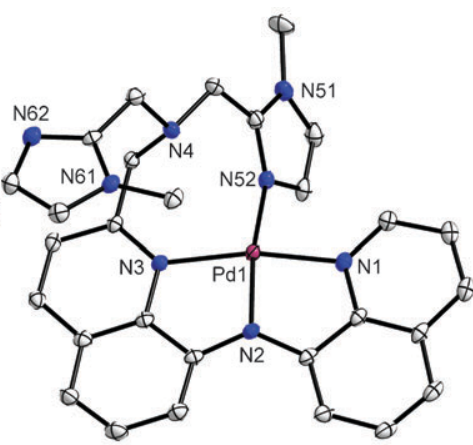

11

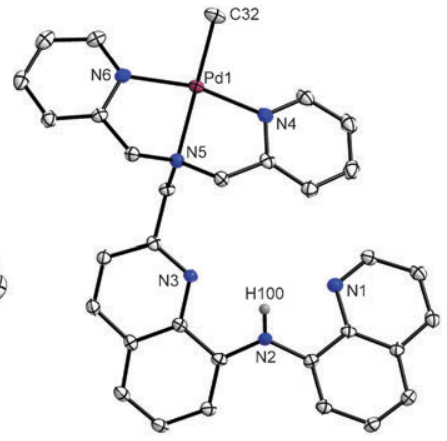

12

Fig. 1 Structures of monometallic complexes 10, 11, and 12. Ellipsoids are shown at the 40\% probability level and hydrogen atoms, solvent molecules, and counteranions (for $\mathbf{1 1}$ and 12) are omitted for clarity.

(see ESI $\dagger$ ). Thus, the ${ }^{1} \mathrm{H}$ NMR behavior of $\mathbf{1 3}$ appears to be consistent with its solid-state structure. We examined the possibility of a $\sigma^{*}\left(\mathrm{~d}_{z^{2}}\right) \rightarrow \sigma\left(\mathrm{p}_{z}\right)$ transition resulting from a $\mathrm{d}^{8}-\mathrm{d}^{8}$ interaction in solution by comparing the electronic absorption spectrum of $\mathbf{1 3}$ with those of its independently prepared monometallic fragments, [ $N$-methyl-bis(pyridin-2-ylmethyl)amine)PdMe $]\left[\mathrm{PF}_{6}\right]$ (see $\mathrm{ESI} \dagger$ ) and (bis(quinolin-8-yl)amido)PdCl. ${ }^{5 a}$ Unfortunately, no such interaction could be rigorously identified, possibly due to overlap with intense ligand-centered $\pi-\pi^{*}$ transitions as suggested elsewhere. ${ }^{13}$

Given that the bimetallic metallation of $\mathbf{8}$ proceeds in a stepwise and selective manner we sought to extend this synthetic strategy to the generation of heterobimetallics. As an illustration, the platinum-containing analog of $\mathbf{1 1}$ can be generated by reaction of 8 with 1 equiv. (COD) $\mathrm{Pt}(\mathrm{Me}) \mathrm{Cl}$ and 1 equiv. $\mathrm{TlPF}_{6}$ to give $\left[\mathrm{L1}^{\mathrm{py}}(\mathrm{H}) \mathrm{PtMe}\right]\left[\mathrm{PF}_{6}\right] \mathbf{1 4}$, the solid- and solution-state structure of which is analogous to that of $\mathbf{1 1}$ based on ${ }^{1} \mathrm{H}$ NMR spectroscopic studies. Further metallation with $(\mathrm{COD}) \mathrm{Pd}(\mathrm{Me}) \mathrm{Cl}$ and catalytic $\mathrm{Et}_{3} \mathrm{~N}$ provides red heterobimetallic $\left[\mathrm{L}^{\mathrm{py}}(\mathrm{PdCl}) \mathrm{PtMe}\right]\left[\mathrm{PF}_{6}\right] \mathbf{1 5}$, which also contains a $\mathrm{d}^{8}-\mathrm{d}^{8}$ interaction in the solid- ${ }^{14}$ and solution-states. The $\mathrm{Pd}-\mathrm{Pt}$ distance of 3.1668(3) $\AA$ is shorter than the sum of the van der Waals radii, $3.35 \AA .{ }^{10}$ DFT calculations support the presence of a d ${ }^{8}-\mathrm{d}^{8}$ interaction (Fig. 4). ${ }^{12}$ The ${ }^{195} \mathrm{Pt}$ NMR chemical shift of $\mathbf{1 5}$ is downfield of that of $\mathbf{1 4}(-3,038$ and $-3,059 \mathrm{ppm} v s$. $\mathrm{K}_{2} \mathrm{PtCl}_{6}$, respectively), which is consistent with donation of electron density to the Pd atom in the solution phase. Ligand 8 offers the potential for the generation of a range of homo- and heterobimetallics and the study of weak metal-metal interactions between metals in different ligand fields.

The procedure for installing Pd into ligand $\mathbf{8}$ may be applied to the related trinucleating ligand $\mathbf{9}$. The room temperature addition of 3 equiv. $\left[\left(\mathrm{CH}_{3} \mathrm{CN}\right)_{4} \mathrm{Pd}\right]\left[\mathrm{BF}_{4}\right]_{2}$ to 9 results in the immediate metallation at the two neutral bis((pyridin-2-yl)methyl)amine sites as determined by ${ }^{1} \mathrm{H}$ NMR spectroscopy. The final palladation of the bis(quinolinyl)amine occurs upon the addition of $\mathrm{Et}_{3} \mathrm{~N}$ and the application of heat. Purple $\left[\mathrm{L}^{\mathrm{py}}(\mathrm{PdBr})_{3}\right]\left[\mathrm{BF}_{4}\right]_{2} \mathbf{1 6}$ is formed when the putative intermediate $\left[\mathrm{L}^{\mathrm{py}}\left(\mathrm{Pd}\left(\mathrm{CH}_{3} \mathrm{CN}\right)\right)_{3}\right]\left[\mathrm{BF}_{4}\right]_{5}$ is treated with 3 equiv. TBABr. The solid-state structure ${ }^{15}$ of $\mathbf{1 6}$ reveals three unique $\mathrm{Pd}$ atoms (Fig. 2); the $\mathrm{Pd} 1-\mathrm{Pd} 2$ distance (3.2447(10) $\AA$ ) is shorter than the sum of the van der Waals radii whereas the Pd2-Pd3 distance (3.4411(10) $\AA$ ) is longer. These bond lengths are consistent with the limiting formulation of two square pyramidal $\mathrm{Pd}$ centers and one that is square planar. Similarly to $\mathbf{1 3}$ and $\mathbf{1 5}, \mathbf{1 6}$ is fluxional in solution as demonstrated by the broad resonances in its ${ }^{1} \mathrm{H}$ NMR spectrum.

The complexation chemistry presented here demonstrates that selective metallation of a polynucleating ligand demands careful tuning of the binding pockets. For example, the BQA site in 7 is metallated with 1 equiv. of a $\mathrm{Pd}(\mathrm{II})$ source whereas metallation of $\mathbf{8}$ occurs most readily at the neutral bis((pyridin-2-yl)methyl)amine site. The modular synthesis of these ligands, in which a multitude 


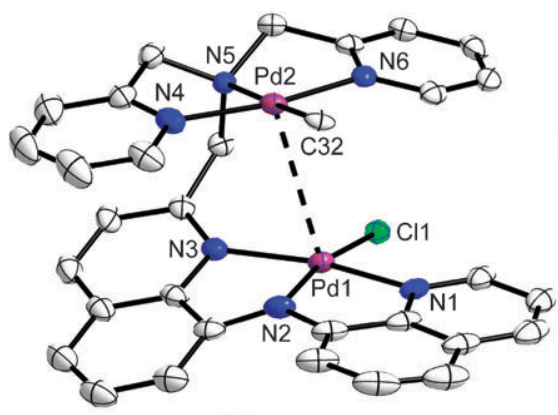

13

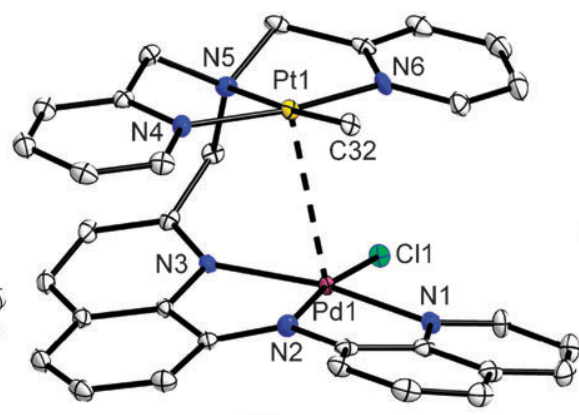

15

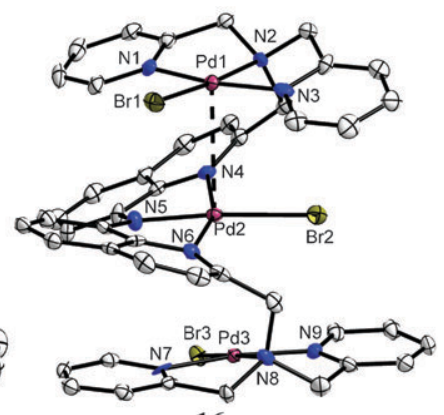

16

Fig. 2 Structures of polymetallic complexes 13, 15, and 16. Ellipsoids are shown at the 40\% probability level and hydrogen atoms, solvent molecules, and counteranions are omitted for clarity.

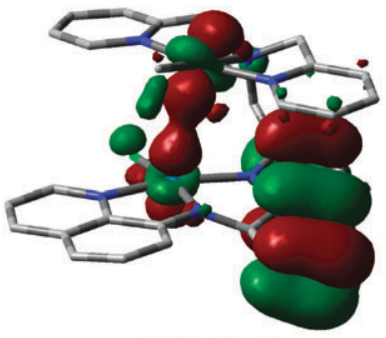

HOMO-10

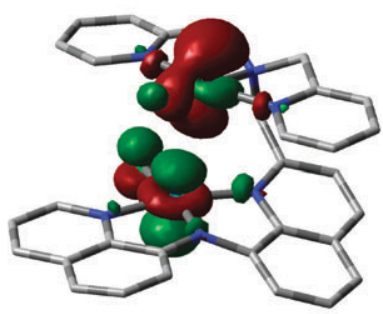

HOMO-1
Fig. 3 Selected calculated molecular orbitals of $\mathbf{1 3} .^{12}$

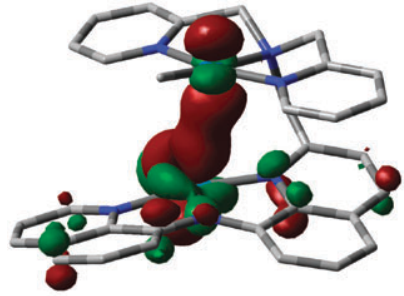

HOMO-10

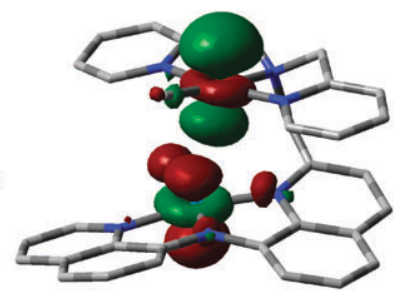

HOMO-1
Fig. 4 Selected calculated molecular orbitals of $15 .^{12}$

of pendant binding pockets can be prepared, allows for such tuning. Further work is directed at studying the electrochemical properties of these and related systems as well as the generation of heterofunctional systems that contain basic and acidic sites for the binding and polarization of non-polar small molecules.

This work was funded in part by the NSF (CHE-0750234). DLMS is grateful for funding from the NSF-GRFP and the MIT Presidential Fellowship Program. Dr Peter Müller is acknowledged for insightful discussions.

\section{Notes and references}

1 (a) E. K. van den Beuken and B. L. Feringa, Tetrahedron, 1998, 54, 12985; (b) Biological Inorganic Chemistry: Structure and Reactivity, ed. H. B. Gray, E. I. Steifel, J. S. Valentine, I. Bertini, University Science Books, USA, 2006, and references therein.

2 Selected examples: (a) D. M. Roundhill, H. B. Gray and C.-M. Che, Acc. Chem. Res., 1989, 22, 55; (b) K.-T. Wan, C.-M. Che and K.-C. Cho, J. Chem. Soc., Dalton Trans., 1991, 1077; (c) E. Baralt and C. M. Lukehart, Inorg. Chem., 1991, 30, 319; (d) W. A. Kalsbeck, D. M. Gingell, J. E. Malinsky and H. H. Thorp, Inorg. Chem., 1994, 33, 3313, and references therein.

3 Selected examples: (a) A. E. Stiegman, S. F. Rice, H. B. Gray and V. M. Miskowski, Inorg. Chem., 1987, 26, 1112; (b) C.-M. Che, V. W.-W. Yam, W.-T. Wong and T.-F. Lai, Inorg. Chem., 1989, 28, 2908-2910; (c) J. A. Bailey, V. M. Miskowski and H. B. Gray, Inorg.
Chem., 1993, 32, 369-370; (d) H.-K. Yip, H. M. Lin, Y. Wang and C.-M. Che, Inorg. Chem., 1993, 32, 3402-3407; (e) B.-H. Xia, C.-M. Che, D. L. Phillips, K.-H. Leung and K.-K. Cheung, Inorg. Chem., 2002, 41, 3866-3875; (f) Q.-J. Pan, H.-X. Zhang, X. Zhou, G.-G. Fu and H.-T. Yu, J. Phys. Chem. A, 2007, 111, 287-294.

4 J. E. Bercaw, M. W. Day, S. R. Golisz, N. Hazari, L. M. Henling, J. A. Labinger, S. J. Schofer and S. Virgil, Organometallics, 2009, 28, 5017.

5 (a) J. C. Peters, S. B. Harkins, S. D. Brown and M. W. Day, Inorg. Chem., 2001, 40, 5083; (b) S. B. Harkins and J. C. Peters, Organometallics, 2002, 21, 1753; (c) S. B. Harkins and J. C. Peters, Inorg. Chem., 2006, 45, 4316.

6 Crystal data for compound 10: $\mathrm{C}_{25} \mathrm{H}_{27} \mathrm{ClN}_{4} \mathrm{O}_{2} \mathrm{Pd}, M=743.14$, monoclinic, $a=5.1225(2) \AA, b=17.5023(7) \AA, c=24.8571(10) \AA$, $\beta=90.583(2)^{\circ}, U=2228.46(15) \AA^{3}, T=173 \mathrm{~K}$, space group $P 2_{1} / c$ (no. 14), $Z=4,42087$ reflections measured, 3997 unique $\left(R_{\text {int }}=\right.$ $0.0226)$, which were used in all calculations. The final $\mathrm{w} R\left(F^{2}\right)$ was $0.0215(I>2 \sigma(I))$ and 0.0216 (all data). CCDC 766171 .

7 Crystal data for compound $\mathbf{1 1} \cdot 2 \mathrm{H}_{2} \mathrm{O} \cdot 2 \mathrm{CHCl}_{3}: \mathrm{C}_{31} \mathrm{H}_{33} \mathrm{Cl}_{7} \mathrm{~N}_{8} \mathrm{O}_{2} \mathrm{Pd}$, $M=904.20$, triclinic, $a=7.3314(7) \AA, b=13.8105(13) \AA, c=$ 18.3307(18) $\AA, \alpha=84.743(2)^{\circ}, \beta=88.483(2)^{\circ}, \gamma=82.262(2)^{\circ}$, $U=1831.2(3) \AA^{3}, T=173 \mathrm{~K}$, space group $P \overline{1}$ (no. 2$), Z=2$, 47572 reflections measured, 9810 unique $\left(R_{\text {int }}=0.0404\right)$, which were used in all calculations. The final $\mathrm{w} R\left(F^{2}\right)$ was 0.0341 $(I>2 \sigma(I))$ and 0.0414 (all data). CCDC 766172.

8 Crystal data for compound 12. $\mathrm{CH}_{3} \mathrm{CN}$ : $\mathrm{C}_{34} \mathrm{H}_{32} \mathrm{~F}_{6} \mathrm{~N}_{7} \mathrm{PPd}, M=$ 790.04, monoclinic, $a=14.6795(13) \mathrm{A}, b=13.2225(11) \AA, c=$ 16.7504(14) $\AA, \beta=91.096(2)^{\circ}, U=3250.7(5) \AA^{3}, T=173 \mathrm{~K}$, space group $P 2_{1} / c$ (no. 14), $Z=4,74757$ reflections measured, 9886 unique $\left(R_{\text {int }}=0.0502\right)$, which were used in all calculations. The final $\mathrm{w} R\left(F^{2}\right)$ was $0.0332(I>2 \sigma(I))$ and 0.0493 (all data). CCDC 766173

9 Crystal data for compound 13-1.5DMSO: $\mathrm{C}_{35} \mathrm{H}_{28} \mathrm{ClF}_{6} \mathrm{~N}_{6} \mathrm{O}_{1.5} \mathrm{PPd}_{2} \mathrm{~S}_{1.5}$, $M=997.94$, monoclinic, $a=16.542(3) \AA, b=32.618(5) \AA, c=$ 14.722(2) $\AA, \beta=109.131(2)^{\circ}, U=7505(2) \AA^{3}, T=173 \mathrm{~K}$, space group $C 2 / c$ (no. 15 ), $Z=8,58464$ reflections measured, 7673 unique $\left(R_{\mathrm{int}}=0.0500\right)$, which were used in all calculations. The final $\mathrm{w} R\left(F^{2}\right)$ was $0.0430(I>2 \sigma(I))$ and 0.0551 (all data). CCDC 766174 .

10 A. Bondi, J. Phys. Chem., 1964, 68, 441-451.

11 K. R. Mann, J. G. Gordon II and H. B. Gray, J. Am. Chem. Soc., $1975,97,3553$.

12 See Supplementary Information $\dagger$ for details. Frisch et al., Gaussian 03, Revision C.02, Gaussian, Inc., Wallingford CT, 2004

13 J. E. Bercaw, A. C. Durrel, H. B. Gray, J. C. Green, N. Hazari, J. A. Labinger and J. R. Winkler, Inorg. Chem., 2010, 49, 1801.

14 Crystal data for compound 15. $\mathrm{CH}_{2} \mathrm{Cl}_{2}: \mathrm{C}_{33} \mathrm{H}_{30} \mathrm{Cl}_{3} \mathrm{~F}_{6} \mathrm{~N}_{6} \mathrm{PPdPt}$, $M=1063.44$, triclinic, $a=7.3949(4) \AA, b=15.6616(8) \AA, c=$ 15.8870(9) $\AA, \alpha=70.729(2)^{\circ}, \beta=81.541(2)^{\circ}, \gamma=86.647(2)^{\circ}$, $U=1717.88(16) \AA^{3}, T=173 \mathrm{~K}$, space group $P \overline{1}$ (no. 2$), Z=2$, 33056 reflections measured, 6077 unique $\left(R_{\text {int }}=0.0318\right)$, which were used in all calculations. The final w $R\left(F^{2}\right)$ was 0.0232 $(I>2 \sigma(I))$ and 0.0234 (all data). CCDC 766175.

15 Crystal data for compound 16.4CH $\mathrm{CH}_{3} \mathrm{CN}$ : $\mathrm{C}_{52} \mathrm{H}_{50} \mathrm{~B}_{2} \mathrm{Br}_{3} \mathrm{~F}_{8} \mathrm{~N}_{13} \mathrm{Pd}_{3}$, $M=1589.60$, orthorhombic, $a=12.8582(13) \AA, b=19.3783(19) \AA$, $c=45.245(4) \AA, U=11273.8(19) \AA^{3}, T=173 \mathrm{~K}$, space group $P b c a$ (no. 61$), Z=8,221928$ reflections measured, 15158 unique $\left(R_{\text {int }}=\right.$ $0.0708)$, which were used in all calculations. The final $\mathrm{w} R\left(F^{2}\right)$ was $0.0905(I>2 \sigma(I))$ and 0.1043 (all data). CCDC 766176 . 